\title{
ON DEFINING AND MEASURING VOLUNTEERING IN THE UNITED STATES AND ABROAD
}

\author{
EMMETT D. CARSON*
}

I

\section{INTRODUCTION}

Even though volunteering has been a distinguishing feature of American society since its inception, scholars continue to struggle with how to accurately describe and measure it. Eleanor Brown's The Scope of Volunteer Activity and Public Service ${ }^{1}$ and Helmut Anheier and Lester Salamon's Volunteering in Cross-National Perspective: Initial Comparisons ${ }^{2}$ demonstrate that nonprofit scholars have yet to provide the conceptual rigor or collect the necessary data that the subject of volunteering warrants.

Although seemingly an easy concept, popular usage and the demands of scholarly precision have made developing an all-purpose definition of volunteering nearly impossible. Even the use of the word "amateurs" in the title of this issue is misleading. "Amateurs," at least as used in everyday conversation, refers to individuals who are not as accomplished or professional as another group. While this may be true of some volunteers, it is unlikely that volunteer firefighters, board members of nonprofit organizations, lawyers who engage in pro bono activities, or medical doctors who work for such groups as the Nobel Prize-winning Doctors Without Borders would describe themselves or should be viewed as amateurs. On the contrary, many of these volunteer groups are the best trained and most experienced at what they do in the entire world.

The observations that follow are divided into three sections. The first section examines the conceptual difficulties in defining volunteering and the implications of excluding or including different notions of volunteering. The second section examines the limitations of the data that is currently available to measure the scope and breadth of volunteering. The last section examines what is known about who is asked to volunteer and the implications for institutions that rely on volunteers to carry out their activities.

Copyright (C) 2000 by Emmett D. Carson

This comment is also available at http://www.law.duke.edu/journals/62LCPCarson.

* President and CEO, Minneapolis Foundation.

1. See Eleanor Brown, The Scope of Volunteer Activity and Public Service, 62 LAW \& CONTEMP. PROBS. 17 (Autumn 1999).

2. See Helmut K. Anheier \& Lester M. Salamon, Volunteering in Cross National Perspective: Initial Comparisons, 62 LAW \& CONTEMP. PROBS. 43 (Autumn 1999). 
II

\section{A QUESTION OF DEFINITION}

Defining what is meant by volunteering and what activities are included is not an easy task. A wonderful review of these definitional challenges can be found in Jon Van Til's Mapping the Third Sector. ${ }^{3}$ These definitional questions become more difficult when volunteering is recognized as a cultural activity that is conditioned by multiple factors including ethnic traditions, religious beliefs, and legal regulations. Many definitions of volunteering exclude activities that may benefit the volunteer's family or friends, although it is unclear how this volunteer work is different from the same work performed for a stranger. Is helping one's sick neighbor with yard work or errands to the grocery store different from performing those tasks for a shut-in member of one's church? Does a narrow view of volunteering as it relates to extended family unduly fail to capture the selflessness of ethnic groups such as Latinos for whom such volunteering and giving represents an important aspect of their community? Similarly, for people who rely on a communal clan structure for organizing their activities, do we discount or ignore their volunteer efforts because they do not conform to a western ideological perspective?

A key issue is whether informal volunteering is as valued as formal volunteering. Informal volunteering refers to engaging in some activity without the umbrella of a formal organization. In contrast, formal volunteering is activity conducted through a formal organization or government program. This is not an insignificant distinction. It may well be that some racial and ethnic groups or nationalities are more likely to engage in informal rather than formal volunteering. If so, the standard approach of focusing on formal volunteering to the exclusion of informal volunteering may unfairly depict the volunteer behavior of these groups.

The definition of volunteering has become so confused by both scholars and the public that it can include both compulsory participation and even remuneration. An increasing trend is for schools to require students to fulfill a public/community-service requirement to graduate. These students are routinely referred to as volunteers, although it is unlikely that in the absence of the requirement there would be $100 \%$ compliance. It is interesting to note that while students fulfilling a mandated community-service requirement are referred to as "volunteers," ex-offenders who are required to perform courtordered community service do not enjoy the same title. This conceptual inconsistency even extends to people who are paid for their "volunteer" work.

A number of volunteer programs pay stipends or provide scholarships to the participants. While the Americorps program is perhaps the best known, the Peace Corps, Volunteers in Service to America ("VISTA"), and other programs also provide salaries or other benefits such as medical insurance. For some young people with few options or little career direction, these benefits

3. John VAN TIL, MAPPING THE THIRd SECTOR 5-17 (1988). 
may be powerful incentives to volunteer. We do not, however, generally think of members of the U.S. volunteer armed services as volunteers, even though they are largely underpaid and are attracted by the benefits of housing, medical care, and tuition scholarships.

It is unlikely that a single definition can cover the different manifestations of volunteering across cultures and capture and neatly explain all of the conceptual difficulties described above. Therefore, it is critical that scholars who study volunteering be aware of the inherent biases in certain definitions and use extreme care in making observations based on those data about the volunteering behavior of different groups.

III

\section{DATA LIMITATIONS}

The divide between various conceptual definitions of volunteering and the available data is enormous. This disparity stems from the twin problems of how and from whom the data is collected as well as what volunteering is understood to include or exclude in the context of the survey. As a result, survey data on volunteering must be scrutinized very closely before making generalizations about who volunteers and how frequently.

The available U.S. data on volunteering is limited; the international data is even more limited. The Current Population Survey ("CPS") data cited by Eleanor Brown is more than ten years old and excludes informal volunteering. As Brown points out, the survey also relies on a single respondent to report on the volunteer activities of the entire household. ${ }^{4}$ Although the data from the independent sector is more current and detailed and measures both informal and formal volunteering, it does not include sufficient sample sizes of African Americans, Asians, or Latinos to generalize the research findings to those groups. Moreover, some questions have been raised about the quality of the data collection method. ${ }^{5}$

The international cross-cultural surveys have an even more difficult task in describing the range of volunteer activity in a way that is meaningful to each group. Without knowing whether a survey includes informal and formal volunteering, and whether paid service is acceptable, it is difficult to interpret the findings. In particular, the data from the Comparative Nonprofit Sector Research Project focuses heavily on Europe, excluding Asia-with the exception of Japan-and Africa. ${ }^{6}$ As a result, it may be less than ideal to draw inferences about worldwide volunteer behavior.

4. See Brown, supra note 1 , at 20 .

5. See Paul G. Schervish \& John J. Havens, Executive Summary, Conclusions, and Recommendations of Kellogg Grant P00020684: Evaluation of the Survey of Giving and Volunteering 2-4 (Mar. 25, 1998) (unpublished project) (on file with the Social Welfare Research Institute at Boston College).

6. See Lester M. SAlamon \& Helmut K. AnHeier, Towards An Understanding of the INTERNATIONAL NONPROFIT SECTOR (Johns Hopkins Comparative Nonprofit Sector Project Working Paper No. 1, 1992). 
Helmut Anheier and Lester Salamon's model of nonprofit sector development posits that there is a relationship between a country's social welfare system and the size of its nonprofit sector. ${ }^{7}$ This theory may well be correct; however, it seems unsupported by the current data in at least three respects. First, the theory relies heavily on the view of volunteers engaged in poverty alleviation and human service delivery in the context of the government-provided social safety net. Volunteers provide a wide variety of tasks that cannot be limited to human service delivery. Second, while the theory asserts that different countries ranked on a government-social-spending scale would have either high or low volunteer involvement, several countries cited seem to refute the hypothesis. Specifically, the United States, the United Kingdom, Sweden, the Netherlands, and Columbia all rank differently on the social-spending scale, and yet forty-six to fifty-one percent of each country's population volunteers. Finally, despite the authors' acknowledgement of the importance of cultural considerations, the model put forward seems devoid of such understanding in recognizing the multiple ways in which different groups of people might volunteer.

\section{IV}

\section{OPPORTUNITY FOR PRACTITIONERS}

There is a growing body of literature to suggest that as it relates to formal volunteering, some people simply are not asked. The Independent Sector data has consistently drawn this conclusion:

It is clear from these findings that young people, single persons, persons from minority groups and people from lower-income households are not asked to volunteer in the same proportions as persons who are white, middle-aged, married, or from middle and upper-income households. ${ }^{8}$

Scholars should therefore be careful in concluding that some groups are more likely to engage in formal volunteering than other groups. To suggest that wealthier and more educated people are inherently more charitable would not be justified by the data, because they are also much more likely to be asked to volunteer.

The idea that significant percentages of the population are not asked to volunteer is not limited to the U.S. Independent Sector data. Anheier and Salamon cite an international study, which found that twenty-eight percent of the respondents did not volunteer because they had not been asked, and eighteen percent because they had not thought about it. If Britain, France, and Germany have stagnating levels of volunteering, as Anheier and Salamon assert, the cause might be a failure to ask citizens to participate.

These findings suggest that the volunteer work force can be significantly increased in both the United States and abroad if people are simply asked.

7. See Anheier \& Salamon, supra note 2 , at 61 .

8. Virginia A. HodgKinson \& MURRAy S. WeITZMAn, GiVING AND VOLUNTEERING IN THE UNITED STATES 118 (1990). 
Given the rapidly changing racial and ethnic demographics of the United States, the institutions that can successfully attract volunteers of color likely will grow and thrive, and those that do not will wither and die.

\section{V}

\section{CONCLUSION}

There is much to be learned through a better understanding of the roles and involvement of volunteers. In a recent Forbes article, Peter Drucker suggests that as businesses seek new ways to motivate and retain a highly educated work force in a labor market where such employees are in great demand, there is a great deal that they could learn from organizations that rely on volunteers."

What motivates-especially knowledge workers-is what motivates volunteers. Volunteers, we know, have to get more satisfaction from their work than paid employees precisely because they do not get a paycheck. They need, above all, challenge. They need to know the organization's mission and to believe in it. They need continuous training. They need to see results. ${ }^{10}$

Drucker's observation underscores the growing importance of understanding and valuing volunteers. The challenge to nonprofit scholars is to develop better explanatory theories on volunteering and to collect more accurate data so that the most basic questions can be answered.

9. Peter F. Drucker, Management's New Paradigms, ForBES, Oct. 5, 1998, at 152.

10. Id. at 166 . 